\title{
Evaluation of Antidiabetic Activity of Ethanolic Extract of Trema Orientalis (L.) Blume Leaves.
}

\author{
Jiji .K.N ${ }^{1 *}$, Pramod.C ${ }^{2}$, Boby S Prasad ${ }^{2}$, DR.P.Muralidharan ${ }^{1}$ \\ ${ }^{1}$ Department of Pharmacology, C.L.Baid Metha College of Pharmacy, Chennai. \\ ${ }^{2}$ University College of Pharmacy, Cheruvandoor, Kottayam, Kerala.
}

\begin{abstract}
:
Context: Trema orientalis(L.)Blume is a species of flowering tree in the hemp family Cannabaceae. This common tree is widely used in African folk medicine for many diseases, for example asthma, cough, dysenteria and hypertension

Objectives: The objective of the study was to evaluate the antidiabetic activity of ethanolic extract of Trema orientalis (L.) Blume leaves by in vivo methods.

Material and methods: The leaves of Trema orientalis were dried under shade and then powdered, and extracted with ethanol by hot continuous extraction method using soxhlet apparatus. Preliminary phytochemical studies were carried out on extract. The antidiabetic potential of ethanolic extract of T.orientalis (EETO) was evaluated by using Streptozotocin-Nicotinamide induced type 2 diabetic rat model. Two doses of the EETO $(250 \mathrm{mg} / \mathrm{kg}$ and $500 \mathrm{mg} / \mathrm{kg})$ were administered to normal and experimental diabetic rats for 14 days. The blood samples were withdrawn from the retro orbital sinus on 1, 7 and $14^{\text {th }}$ days of extract administration and fasting blood glucose levels were estimated. In addition, changes in body weight and serum lipid profiles, assessed in the extract treated diabetic rats were compared with diabetic control and normal animals. OGTT and histopathological studies of pancreas were also performed.

Results and discussion: The study showed that, extract treatment in diabetic rats at two dose levels showed a decrease in fasting blood glucose levels. The total cholesterol and serum triglycerides levels were also reduced and the HDL cholesterol levels were increased upon treatment with the extract thus proving the potent antidiabetic property of the plant. Recovery of body weight of extract treated diabetic rats gave further evidence for dose related antidiabetic activity of EETO. The extract did not produce any significant effects on normal animals but significantly increases glucose tolerance of normal animals, which further confirms the safety and antidiabetogenic action of the extract.
\end{abstract}

Conclusion:The study confirmed the potent antidiabetic activity of the plant Trema orientalis (L.) Blume.

Keywords: Diabetes mellitus, Antidiabetic activity, Oral glucose tolerance test.

\section{Introduction}

Diabetes mellitus is a complex and a multifarious group of disorders that disturbs the metabolism of carbohydrates, fat and protein. It results from shortage or lack of insulin secretion or reduced sensitivity of the tissue to insulin [1]. Diabetes is a chronic medical condition, it can be controlled by medication and lifestyle modification throughout the life span. The clinical manifestation leading damage to the small blood vessels, referred to as microvascular disease. Diabetes is also an important factor in accerating the hardening and narrowing the arteries (atherosclerosis), leading to strokes, coronary heart disease, and other large blood vessel diseases. This is referred to as macrovascular diseases [2].

Currently there are over 150 million diabetics worldwide and this is likely to increase to 300 million or more by the year 2025 [3][4].Statistical projection about India suggest that the number of diabetics will rise from 15 million in 1995 to 57 million in the year 2025 making it the country with highest number of diabetics in the world [3]. This dreadful disease is found in all parts of world and is becoming a serious threat to mankind. A lot of synthetic chemical agents are available to control and treat diabetic patients, but total recovery from diabetes has not been reported till the date. Plants provide a potential source of hypoglycemic drugs and are widely used in several traditional system of medicine. The effects of these plants may delay the development of diabetic complications and correct the metabolic abnormalities by various mechanisms [5]. Currently available oral antihyperglycemic agents in clinical use have characteristic profile of side effects. Management of diabetes with agents devoid of any side effects is still a challenge to the medical system. This has led to an increase in the demand for natural products with antihyperglycemic activity having fewer side effects [6]. It is therefore imperative that the larger number of crude drugs which are in use as complementary and alternative medicine claiming to be useful in diabetes, be subjected to scientific evaluation. Traditional antidiabetic plants might provide a new oral hypoglycemic compounds, which can counter the high cost and poor availability of the current medicine present day drugs for many rural populations in developing countries [7][8]. 
Trema orientalis(L.)Blumeis a species of flowering tree in the hemp family Cannabaceae. This common tree is widely used in African folk medicine for many diseases, for example asthma, cough, dysenteria and hypertension [9].The root of this plant has been used for treatment of trauma, blood stasis, hematuria and bleeding of intestine and stomach [10][11].The root, bark and leaves are used in epilepsy. The stem bark is used as a poultice for muscular pain [12]. The study aims to scientifically evaluate whether the ethanolic leaf extract of T.orientalis has antidiabetic property.

\subsection{Chemicals and regeants}

\section{Materials And Methods}

Streptozotocin obtained from Himedia (Mumbai, India). Nicotinamide and glibenclamide were obtained from (Alcon Pharmaceuticals, Mumbai). All other chemicals and reagents used were of analytical grade.

\subsection{Plant materials}

The fresh leaves of $T$. orientaliswere collected fromKottayam M G University Campus on $5^{\text {th }}$ April 2012. The plant was identified and authenticated from School of Environmental science, M.G University, Kottayam. A voucher specimen (SES.M.G.UTY NO. 1458) is preserved at the Herbarium of School of Environmental science, M.G University, Kottayam.Freshly collected plant materials were washedunder running tap water and distilled water to removeadhering dust and then dried under shade. The driedsamples were powdered in a Mechanical grinder and usedfor solvent extraction.

\subsection{Solvent extraction}

The extraction of the dried powdered plant samples were carried out by hot continuous extraction method in Soxhlet extractor with ethanol as solvent for $10 \mathrm{~h}$. The extract obtained was collected and concentrated by gentle heating followed by using vacuum evaporator. The concentrated extract was weighed and the percentage yield was calculated. Then the extract was subjected to Preliminary Phytochemical Evaluation.

\subsection{Pharmacological evaluation \\ 2.4.1Experimental animals}

Healthy adult Wistar male albino rats between 4 to 8 weeks of age and weighing about $150-250 \mathrm{~g}$ were used for the study. Animals were procured from the animal house of University College of Pharmacy, Cheruvandoor. Housed in polypropylene cages at a temperature of $25-30^{\circ} \mathrm{C}$ and relative humidity $35-45 \%$, light and dark cycles of 12 and $12 \mathrm{~h}$ respectively for one week before and during the experiments. Animals were provided with standard rodent pellet diet (Dayal Industries, Banglore) and the food was withdrawn 12-18 h before the experiment though water was allowed ad libitum. All studies were performed in accordance with the guide for the care and use of laboratory animals, and approved by the Institutional Animal Ethical Committee of UCP, Cheruvandoor, Kottayam, India (010/MPH/UCP/CVR/12).

\subsubsection{Preparation of the test samples}

Extract as well as drug was suspended in $0.5 \%$ carboxymethyl cellulose (CMC) in distilled water prior to oral administration to the experimental animals.

\subsubsection{Effect Of Ethanolic Extract Of T.orientalis Leaves In Normoglycemic Rats}

Effect of EETO in normoglycemic rats was evaluated by a method described by Shirwaikar et al[13].For normoglycaemic study, over night fasted animals were randomly divided into four groups of six anmals each.

Group I - Normal Control rats received vehicle solution.

Group II - $\quad$ Normal rats treated with EETO $250 \mathrm{mg} / \mathrm{kg}$ body weight.

Group III - $\quad$ Normal rats treated with EETO $500 \mathrm{mg} / \mathrm{kg}$ body weight.

Group IV - Normal rats treated with glibenclamide $0.6 \mathrm{mg} / \mathrm{kg}$ body weight suspended in aqueous Solution [14].

The vehicles and the drug/extract were administered orally using intra gastric tube daily for 2 weeks. The blood samples were withdrawn from the retro orbital sinus on 1,7 and $14^{\text {th }}$ days of extract administration. The fasting blood glucose levels were estimated by glucose oxidase-peroxidase reactive strips and a glucometer(ONE TOUCH select simple, manufactured by Johnson's \& Johnson Ltd,India). 


\subsubsection{Oral Glucose Tolerance Test (OGTT)}

The oral glucose tolerance test was performed in overnight fasted (18 h) normal rats by a method described by Shirwaikar et al[15]. Rats divided into four groups, each group contains six animals.

Group I - $\quad$ Normal Control rats received vehicle solution.

Group II - $\quad$ Normal rats treated with glibenclamide $0.6 \mathrm{mg} / \mathrm{kg}$ body weight suspended in aqueous Solution [14].

Group III - $\quad$ Normal rats treated with EETO $250 \mathrm{mg} / \mathrm{kg}$ body weight.

Group IV - $\quad$ Normal rats treated with EETO $500 \mathrm{mg} / \mathrm{kg}$ body weight.

Glucose $(3 \mathrm{~g} / \mathrm{kg})$ was fed 30 min after the administration of extracts. Blood was withdrawn from the retro orbital sinus at $0,30,60,90$, and $180 \mathrm{~min}$ of glucose administration and glucose levels were estimated using glucose oxidase-peroxidase reactive strips and a glucometer $(O N E$ TOUCH select simple, manufactured by Johnson's \& Johnson Ltd,India).

\subsubsection{Effect of ethanolic extract of T.orientalis leaves in Streptozotocin-Nicotinamide Type2 diabetic rats[15]. Induction of non-insulin-dependent diabetes mellitus (NIDDM)}

Non-insulin-dependent diabetes mellitus was induced in rats by a method described by Shirwaikar et al[15]. NIDDM was induced in overnight fasted adult Wistar strain albino male rats by a single intraperitoneal injection of $60 \mathrm{mg} / \mathrm{kg}$ streptozotocin , $15 \mathrm{~min}$ after the i.p. administration of $120 \mathrm{mg} / \mathrm{kg}$ of nicotinamide. Streptozotocin (STZ) was dissolved in citrate buffer $(\mathrm{pH} \mathrm{4.5)}$ and nicotinamide was dissolved in normal saline. Hyperglycemia was confirmed by the elevated glucose levels in plasma, determined at $72 \mathrm{~h}$ and then on day 7 after injection. Only rats found with permanent NIDDM were used for the antidiabetic study.

\section{Experimental design}

Animals were divided into five groups of six rats each. The extract was administered for 14 days.

Group I - Diabetic Control rats received vehicle solution.

Group II - Diabetic rats treated with glibenclamide $0.6 \mathrm{mg} / \mathrm{kg}$ body weight

suspended in aqueous Solution, for 14 days [14]

Group III- Diabetic rats treated with EETO $250 \mathrm{mg} / \mathrm{kg}$ body weight.

Group IV - Diabetic rats treated with EETO $500 \mathrm{mg} / \mathrm{kg}$ body weight.

Group V - Normal Control rats received vehicle solution.

The effects of administration of EETO to diabetic rats were determined by measuring fasting blood glucose levels, serum lipid profiles, and initial and final changes in body weight. Day 7 of induction was designated as day 1 for extract administration in diabetic rats. Fasting blood glucose was estimated on days 1, 7, and 14 of extract administration using glucose oxidase-peroxidase reactive strips and a glucometer (ONE TOUCH select simple, manufactured by Johnson's \& Johnson Ltd,India). All other biochemical parameters were determined on day 14 after the animals were sacrificed by cervical dislocation. Serum lipid profiles were measured by an autoanalyser (AGAPPE Diagnostics, SEACRADIM company, MISPAPLUS model) using lipid profile estimating kits (AGAPPE Diagnostic kits)

\section{Histopathological examination [15]}

Histopathological parameters were studied at the Dianova Laboratories (A Unit of Dianova Diagnostics Pvt. Ltd ), Kottayam, India, under the guidance of Dr.Rosamma Thomas MD, D.C.P.

On day 14 when the animals were sacrificed, the pancreas, of one animal from each group was excised and stored in $10 \%$ formalin after washing with normal saline. The tissue was washed, dehydrated with alcohol, cleared with xylene and paraffin blocks were made. Serial sections of $5 \mu \mathrm{m}$ thickness were cut using a rotary microtome. The sections were then deparaffinised with xylene and hydrated in descending grades of alcohol. The slides were then transferred to haematoxylin for $10 \mathrm{~min}$, followed by rinsing with water. These were examined and later counterstained with eosin, rinsed with water, dehydrated with ascending grades of alcohol, cleared with xylene and mounted and observed under light microscope for the pathological symptoms to assess any architectural changes occurring in pancreas.

\subsection{Statistical analysis}

Data were statistically evaluated using one-way ANOVA, followed by Dunnett's multiple comparison test using GraphPad Prism 6 version computer software.

\section{Results}


In the present investigation, ethanolic extract extracted using conventional soxhlet extraction technique in leaves of T.orientaliswas examined for its in vivo antidiabetic activity. The percentage yield obtained after the ethanolic extraction of dried leaves of Trema orientalis (L.) Blume was $10.02 \% \mathrm{w} / \mathrm{w}$. The phytochemical screening result showed that EETO contains high amounts of phenolics, tannins, flavanoids and terpenoids.Other constituents like saponins and alkaloids were present in low amounts.

\section{Results Of In Vivo Pharmacological Evaluation}

\subsection{Effect of ethanolic extract of T.orientalis leaves in normoglycemic rats}

Blood glucose level of animals in all groups were recorded at $1^{\text {st }}, 7^{\text {th }}$ and $14^{\text {th }}$ day. Data obtained were tabulated in the table 3.1

Table 3.1 Effect of EETO on blood glucose level (mg/dl) of normoglycemic rats

\begin{tabular}{|l|l|l|l|l|l|}
\hline Gp.no & Treatment & \multirow{2}{*}{ Dose $(\mathrm{mg} / \mathrm{kg})$} & \multicolumn{3}{|l|}{ Blood glucose level $(\mathrm{mg} / \mathrm{dl})$} \\
\cline { 4 - 6 } & & & DAY 1 & DAY 7 & DAY 14 \\
\hline I & Vehicle control & - & $75.33 \pm 2.19$ & $73.5 \pm 1.23$ & $73.17 \pm 1.38$ \\
\hline II & Glibenclamide & 0.6 & $74.17 \pm 2.09$ & $67 \pm 1.75^{*}$ & $64.83 \pm 2.57^{*}$ \\
\hline III & EETO & 250 & $74 \pm 1.93$ & $72.33 \pm 1.56$ & $71.67 \pm 1.23$ \\
\hline IV & EETO & 500 & $74.67 \pm 2.88$ & $72.5 \pm 0.85$ & $71.17 \pm 1.58$ \\
\hline
\end{tabular}

Values are statistically evaluated by One Way ANOVA followed by Dunnett's Multiple Comparison Test.

* Represents statistical significance vs.control $(p<0.05)$

Values are expressed as mean \pm S.E.M, $n=6$ for each group .

From the above tabulated data it is clear that, in normal animals treated with EETO at two dose levels $(250 \mathrm{mg} / \mathrm{kg}$ and $500 \mathrm{mg} / \mathrm{kg}$ respectively), no significant reduction in the blood glucose level was observed as compared to the normal control (Group I).But in group IV animals (treated with $0.6 \mathrm{mg} / \mathrm{kg}$ of standard drug glibenclamide) a slight progressive decrease in blood glucose level was found during the study $(p<0.05)$ as compared to the normal control group.

\subsection{Oral Glucose Tolerance Test (OGTT)}

Blood glucose level of animals in all groups were recorded after every 0, 30, 60, 90 and 180 minutes. Data obtained were tabulated in the table 3.2.

Table 3.2 Effect of EETO on OGTT

\begin{tabular}{|c|c|c|c|c|c|c|c|}
\hline \multirow[t]{2}{*}{ Gp.no } & \multirow[t]{2}{*}{ Treatment } & \multirow{2}{*}{$\begin{array}{l}\text { Dose } \\
(\mathrm{mg} / \mathrm{kg})\end{array}$} & \multicolumn{5}{|c|}{ Blood glucose level (mg/dl) } \\
\hline & & & $0 \mathrm{~min}$ & $30 \mathrm{~min}$ & $60 \mathrm{~min}$ & $90 \min$ & $180 \mathrm{~min}$ \\
\hline $\mathrm{I}$ & Vehicle control & - & $72 \pm 1.88$ & $130.83 \pm 2.57$ & $119 \pm 2.92$ & $106.17 \pm 2.56$ & $70.83 \pm 0.87$ \\
\hline II & Glibenclamide & 0.6 & $71.17 \pm 1.01$ & $97.5 \pm 3.67 * *$ & $82 \pm 2.98 * * *$ & $70 \pm 0.97 * * *$ & $67 \pm 1.91$ \\
\hline III & EETO & 250 & $73.33 \pm 1.69$ & $119.67 \pm 2.6^{*}$ & $101.17 \pm 2.2^{*}$ & $91 \pm 2.97 *$ & $70.5 \pm 2.3$ \\
\hline IV & EETO & 500 & $72 \pm 2.77$ & $101 \pm 3.97 * *$ & $89 \pm 3.16^{* *}$ & $77 . \pm 0.86^{* * *}$ & $69.67 \pm 2.19$ \\
\hline
\end{tabular}

Values are statistically evaluated by One Way ANOVA followed by Dunnett's Multiple Comparison Test.

* Represents statistical significance of treatment groups vs. Normal Control $(p<0.05)$

$* *$ Represents statistical significance of treatment groups vs. Normal Control $(p<0.01)$

$* * *$ Represents statistical significance of treatment groups vs. Normal Control $(p<0.001)$

Values are expressed as mean \pm S.E.M,n $=6$ for each group .

In this study, it was observed that within 30 minutes of starting the glucose tolerance test, blood glucose concentration almost doubled from its initial level of control. This hyperglycemia was maintained until 90minutes and then began to decrease. The three treatment groups (Group II, III, and IV) significantly blocked the elevation in blood glucose level after glucose administration, Glibenclamide blocked the hyperglycemia moderate significantly $(p<0.01)$ at 30 minutes and highly significantly $(p<0.001)$ at 60 and 90 minutes of glucose administration as compared to normal control. The EETO at a dose level of $500 \mathrm{mg} / \mathrm{kg}$ blocked the hyperglycemia moderate significantly $(p<0.01)$ at 30,60 minutes and highly significantly $(p<0.001)$ at 90 minutes of glucose administration as compared to normal control. The EETO at a dose of $250 \mathrm{mg} / \mathrm{kg}$ significantly $(p<0.05)$ blocked the increase in blood glucose level after glucose administration from 30 minutes onwards as compared to Group I (Normal Control) animals.

\subsection{Effect of ethanolic extract of T.orientalis leaves in Streptozotocin- Nicotinamide type 2 diabetic rats 3.3.1 Effect on blood glucose level}

Blood glucose level of animals in all groups were recorded on $1^{\text {st }}, 7^{\text {th }}$ and $14^{\text {th }}$ day. Data obtained were tabulated in the table 3.3.1

Table 3.3.1 Effect of EETO on blood glucose level $(\mathrm{mg} / \mathrm{dl})$ of diabetic rats 
Evaluation Of Antidiabetic Activity Of Ethanolic Extract Of Trema Orientalis (L.) Blume Leaves.

\begin{tabular}{|l|l|l|l|l|l|}
\hline \multirow{2}{*}{ Gp.no } & Treatment & \multirow{2}{*}{$\begin{array}{l}\text { Dose } \\
\end{array}$} & & \multicolumn{4}{|c|}{ Blood glucose level $(\mathrm{mg} / \mathrm{dl})$} \\
\cline { 4 - 6 } & & $(\mathrm{mg} / \mathrm{kg})$ & DAY 1 & DAY 7 & DAY 14 \\
\hline I & Vehicle control & - & $286.5 \pm 13.18$ & $281.33 \pm 12.09$ & $282.5 \pm 10.49$ \\
\hline II & Glibenclamide & 0.6 & $281.67 \pm 11.70$ & $149.67 \pm 4.09^{* * * *}$ & $116.5 \pm 4.69^{* * *}$ \\
\hline III & EETO & 250 & $290.5 \pm 5.11$ & $222.67 \pm 4.09^{*}$ & $149.5 \pm 4.20^{* * *}$ \\
\hline IV & EETO & 500 & $283.83 \pm 7.99$ & $187.33 \pm 3.40^{* *}$ & $121.17 \pm 2 . .06^{* * *}$ \\
\hline V & Normal control & - & $75.33 \pm 2.19^{* * *}$ & $73.5 \pm 1.23^{* * *}$ & $72.83 \pm 1.47^{* * *}$ \\
\hline
\end{tabular}

Values are statistically evaluated by One Way ANOVA followed by Dunnett's Multiple Comparison Test.

*Represents statistical significance of treatment groups vs. Diabetic Control. $(p<0.05)$

$* *$ Represents statistical significance of treatment groups vs. Diabetic Control. $(p<0.01)$

$* * *$ Represents statistical significance of treatment groups vs. Diabetic Control. $(p<0.001)$

Values are expressed as mean \pm S.E.M, $\mathrm{n}=6$ for each group .

Progressive decrease in blood glucose level was found in all three treatment groups during study. On day 7 of extract/drug administration, in EETO $250 \mathrm{mg} / \mathrm{kg}$ treated group, EETO $500 \mathrm{mg} / \mathrm{kg}$ treated group, and Glibenclamide $0.6 \mathrm{mg} / \mathrm{kg}$ treated group, blood glucose level was decreased significantly ( $p<0.05, p<0.01$ and $p<0.001$ respectively) as compared to diabetic control group. At the end of experiment (on day 14), all the three treatment groups ( Group II, III and IV) showed a significant $(p<0.001)$ reduction in the fasting blood glucose level as compared to diabetic control rats (Group I).

\section{EFFECT ON BLOOD GLUCOSE LEVEL}

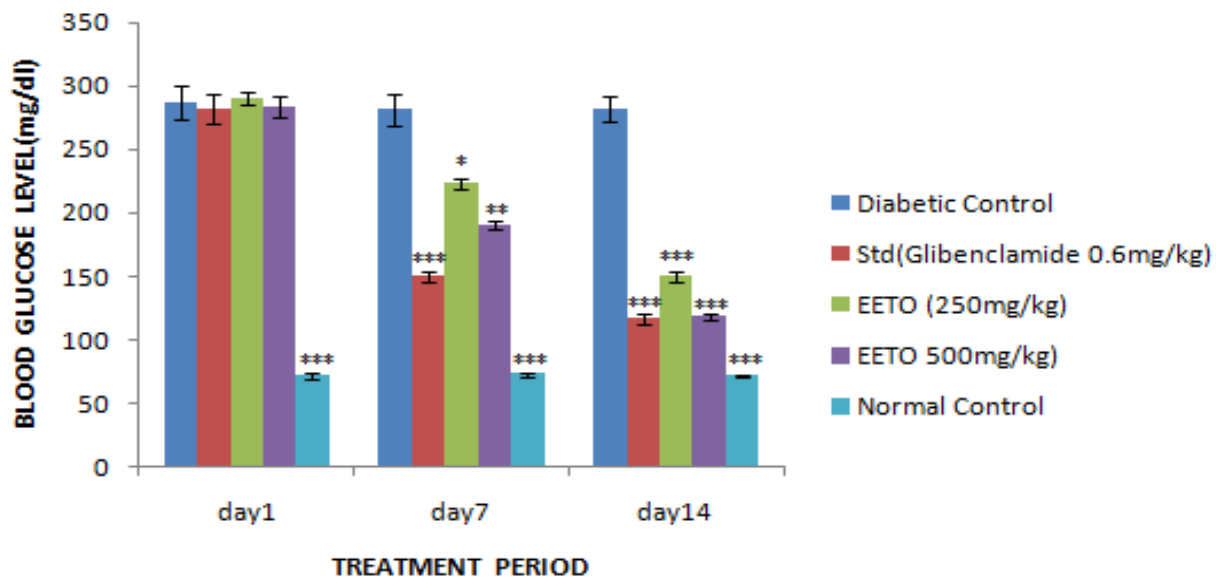

Figure 3.3.1: Effect of ethanolic extract of T.orientalis leaves on blood glucose level (mg/dl) of diabetic rats

\subsubsection{Effect on serum lipid profile}

In the Diabetic control group, total cholesterol and triglycerides, increased and HDL level decreased when compared to normal group. In the EETO $(250 \mathrm{mg} / \mathrm{kg})$ and Glibenclamide $(0.6 \mathrm{mg} / \mathrm{kg})$ treated groups, total cholesterol and triglycerides decreased significantly $(p<0.05, p<0.05$ respectively), while in animals treated with EETO $(500 \mathrm{mg} / \mathrm{kg})$ total cholesterol and triglycerides decreased significantly $(p<0.01)$ as compared to diabetic control group. In animals treated with EETO $(250 \mathrm{mg} / \mathrm{kg})$ and Glibenclamide $(0.6 \mathrm{mg} / \mathrm{kg})$,as compared to diabetic control group (Group I), HDL cholesterol increased significantly ( $p<0.05, p<0.05$ respectively), while in EETO $(500 \mathrm{mg} / \mathrm{kg})$ treated group, HDL cholesterol increased significantly at $(p<0.05)$.

Table 3.3.2: Effect of ethanolic extract of T.orientalis leaves on lipid profile of diabetic rats

\begin{tabular}{|l|l|l|l|}
\hline GROUP & \multicolumn{1}{|c|}{ TC(mg/dl) } & \multicolumn{1}{|c|}{ TG(mg/dl) } & \multicolumn{1}{c|}{ HDL } \\
\hline I.(Diabetic Rats+Vehicle) & $180.33 \pm 3.72$ & $169.67 \pm 2.69$ & $15.67 \pm 0.95$ \\
\hline II.(Diabetic Rats +Glibenclamide 0.6mg/kg) & $147.67 \pm 3.71^{*}$ & $150.17 \pm 4.41^{*}$ & $23.83 \pm 1.22^{*}$ \\
\hline III.(Diabetic Rats+ EETO $250 \mathrm{mg} / \mathrm{kg})$ & $157.83 \pm 3.75^{*}$ & $152.33 \pm 2.01^{*}$ & $21.50 \pm 0.88^{*}$ \\
\hline IV.(Diabetic Rats +EETO $500 \mathrm{mg} / \mathrm{kg})$ & $141.83 \pm 4.09^{* *}$ & $130.67 \pm 4.20^{* *}$ & $32.17 \pm 2.05^{* *}$ \\
\hline V.(Normal rats +Vehicle) & $76.67 \pm 1.67 * * *$ & $80.33 \pm 1.28^{* * *}$ & $35.00 \pm 0.73^{* * *}$ \\
\hline
\end{tabular}

Values are statistically evaluated by One Way ANOVA followed by Dunnett's Multiple Comparison Test.

$*$ Represents statistical significance of treatment groups vs. Diabetic Control $(p<0.05)$

** Represents statistical significance of treatment groups vs. Diabetic Control $(p<0.01)$

*** Represents statistical significance of treatment groups vs. Diabetic Control $(p<0.001)$

Values are expressed as mean \pm S.E.M, $\mathrm{n}=6$ for each group. 


\subsubsection{Effect on changes in body weight of diabetic rats}

Body weight of animals in all groups were recorded on $1^{\text {st }}, 7^{\text {th }}$ and $14^{\text {th }}$ and day. Data obtained were tabulated in the table 3.3.3.

Table 3.3.3 Effect of EETO in changes in body weight $(\mathrm{g})$ of diabetic rats

\begin{tabular}{|l|l|l|l|l|l|}
\hline Gp.no & Treatment & Dose $(\mathrm{mg} / \mathrm{kg})$ & \multicolumn{3}{|l|}{ Body weight $(\mathrm{g})$} \\
\cline { 4 - 6 } & & & DAY 1 & DAY 7 & DAY 14 \\
\hline I & Vehicle control & - & $191.67 \pm 7.92$ & $168.33 \pm 9.46$ & $151.67 \pm 10.46$ \\
\hline II & Glibenclamide & 0.6 & $193.33 \pm 10.22$ & $178.33 \pm 10.14$ & $188.33 \pm 9.10^{*}$ \\
\hline III & EETO & 250 & $190 \pm 10.65$ & $170 \pm 11.83$ & $176.67 \pm 11.16$ \\
\hline IV & EETO & 500 & $191.67 \pm 7.92$ & $176.67 \pm 6.67$ & $190 \pm 5.16^{*}$ \\
\hline V & Normal control & - & $190 \pm 5.77$ & $193.33 \pm 4.94^{*}$ & $201.67 \pm 6.01^{* *}$ \\
\hline
\end{tabular}

Values are statistically evaluated by One Way ANOVA followed by Dunnett's Multiple Comparison Test.

*Represents statistical significance vs.diabetic control $(\mathrm{p}<0.05)$

**Represents statistical significance vs. diabetic control $(\mathrm{p}<0.01)$

Values are expressed as mean \pm S.E.M, $n=6$ for each group.

Significant change in body weight during study period was found to be in diabetic control group which decreased significantly as compared to normal control group.In animals treated with EETO (500mg/kg) and Glibenclamide $(0.6 \mathrm{mg} / \mathrm{kg})$ the body weight increased significantly ( $p<0.05, p<0.05$ respectively) by $14^{\text {th }}$ day as compared to diabetic control group. EETO $(250 \mathrm{mg} / \mathrm{kg})$ treated group animals showed a non significance increase in the body weight when compared with Group I animals.

\section{EFFECT ON CHANGES IN BODY WEIGHT}

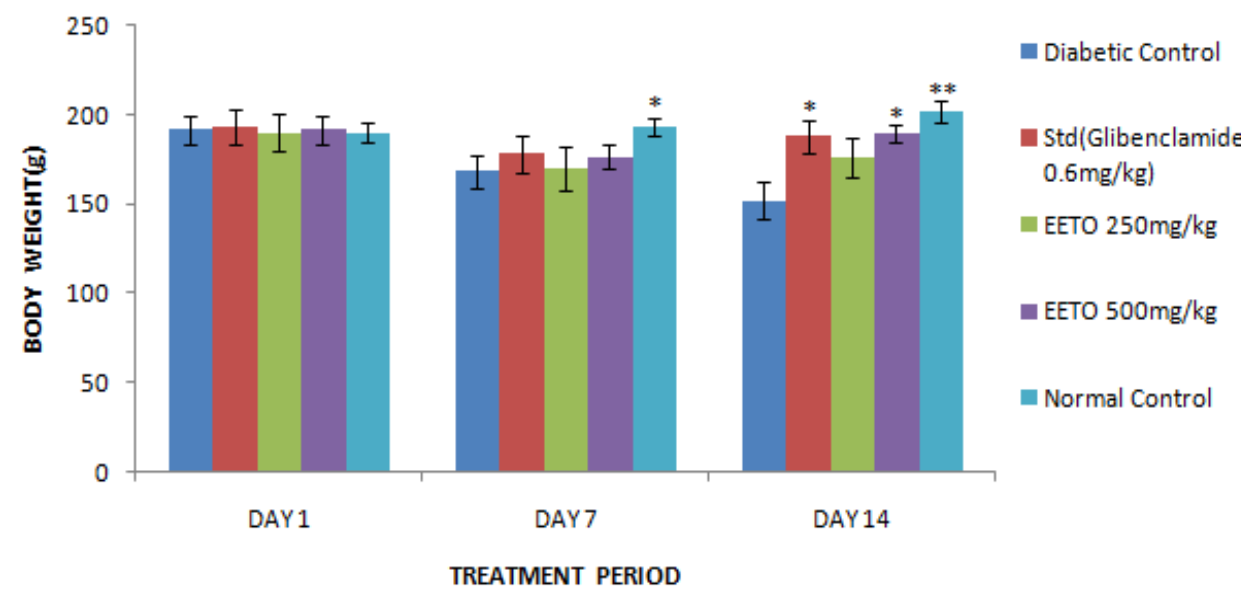

Figure 3.3: Effect of ethanolic extract of T.orientalis leaves on changes in body weight of diabetic rats

\subsection{Histopathological studies}

- Group V - Normal pancreas shows exocrine pancreas affixed with clusters of islets cells (Picturised by Long-arrow in the Figure 3.4a). Cells in the islets of Langerhans appeared with normal acini and normal population. (Picturised by Short-arrow in the Figure 3.4a).

- Group I - Exocrine pancreatic tissue affixed with decreased number of islets of Langerhans (Picturised by Long-arrow in the Figure 3.4b). Individual islets also shows decreased number of cells (Picturised by Short-arrow in the Figure 3.4b) with vacuolation cytoplasm (Picturised by Arrow head in the Figure 3.4b).

- Group II - Exocrine pancreas affixed with clusters of islets (Picturised by Long-arrow in the Figure 3.4c), with near normal cellular distribution (Picturised by Short-arrow in the Figure 3.4c).

- Group III - Few clusters of islets present among the exocrine pancreas (Picturised by Long-arrow in the Figure 3.4d). Number of cells in each islets is less as compared to normal (Picturised by Short-arrow in the Figure 3.4d).

- Group IV - Exocrine pancreatic tissue affixed with normal number of islets of Langerhans (Picturised by Long-arrow in the Figure 3.4e). Number of cells in each islets cluster appeared normal, no vacuolation of the individual cells (Picturised by Short-arrow in the Figure 3.4e). 


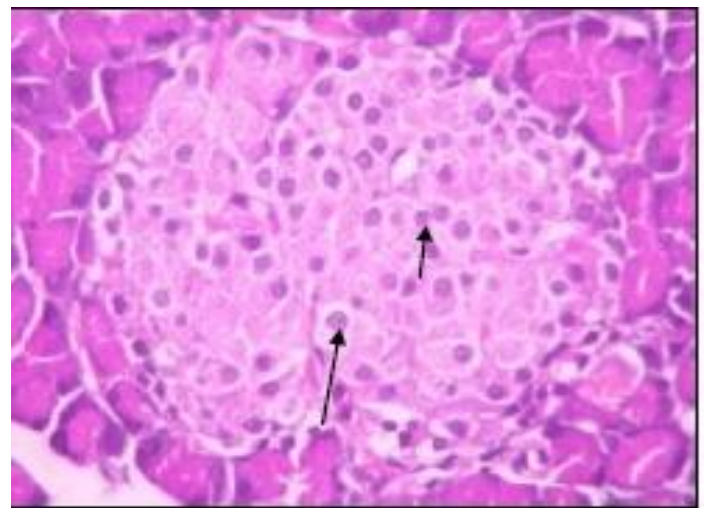

Figure 3.4a: Pancreas of Group V Rat ( Normal Control)

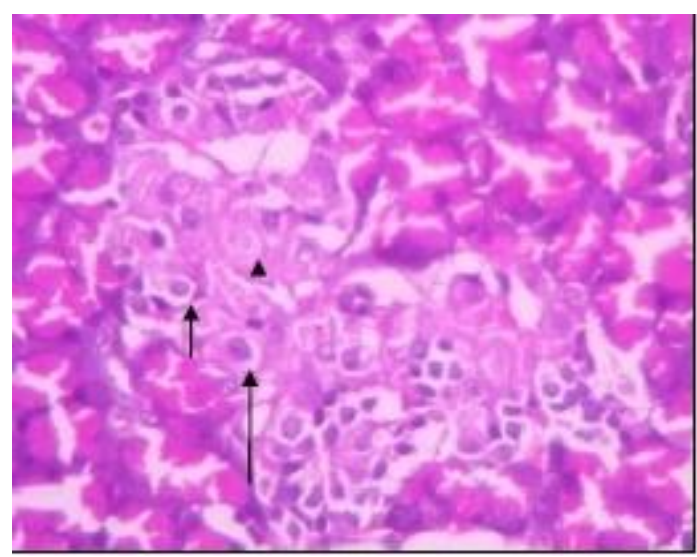

Figure 3.4b: Pancreas of Group I Rat ( Diabetic Control)

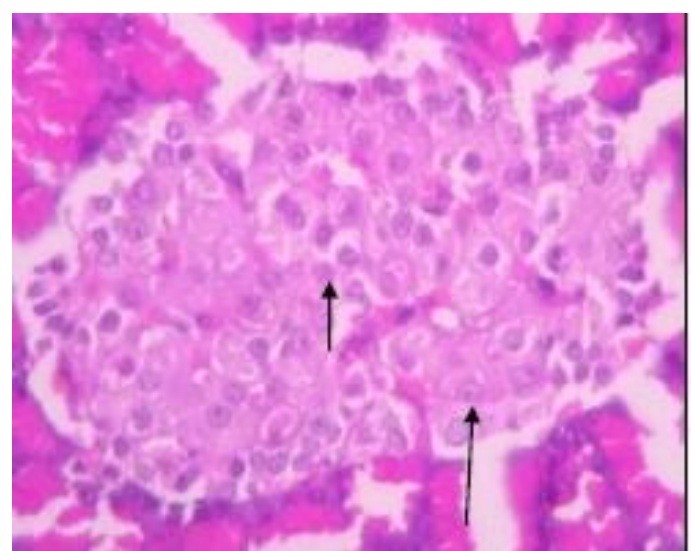

Figure 3.4c: Pancreas of Group II Rat ( Diabetic Rat + glibenclamide 0.6mg/kg )

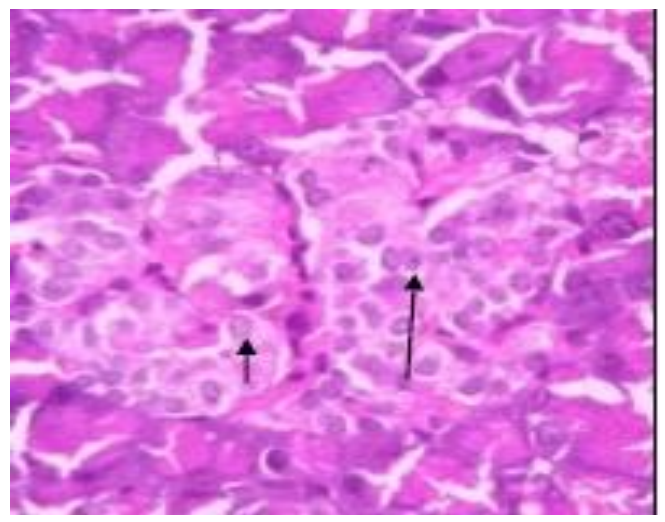

Figure 3.4d: Pancreas of Group III Rat ( Diabetic Rat + EETO 250mg/kg) 


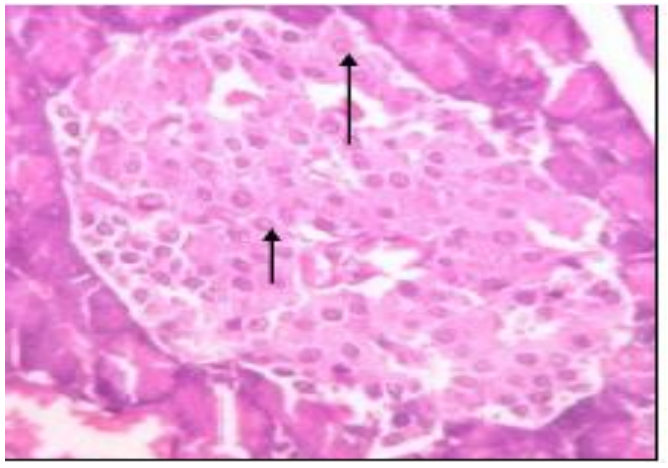

Figure 3.4e: Pancreas of Group IV Rat (Diabetic Rat + EETO 500mg/kg)

\section{Discussion}

Present study indicates anti-diabetic and hypolipidemic effect of ethanolic extract of Trema orientalis(L.)Blumein STZ - Nicotinamide induced type 2 diabetes in male Albino wistar rats. Over-production (excessive hepatic glycogenolysis and gluconeogenesis) and decreased utilization of glucose by the tissues are the fundamental basis of hyperglycemia in diabetes mellitus [16]. Persistent hyperglycemia, the common characteristic of diabetes can cause most of the diabetic complications. In all patients, treatment should aim to lower elevated blood glucose level to near-normal levels [17].

OGTT referred to as the glucose tolerance test, measures the body's ability to metabolize glucose, or clear it out of the bloodstream. The test reveals how quickly glucose is metabolized from the bloodstream for use by cells as an energy source [18]. In OGTT both $250 \mathrm{mg} / \mathrm{kg}$ and $500 \mathrm{mg} / \mathrm{kg}$ dose of EETO shows promising results (Table 3.2 and Figure 3.2), by this investigation it can be suggested that the mode of action of the EETO is probably mediated by an enhancedsecretion of insulin. Various studies on medicinal plants have reported a similar promising results in OGTT $[\mathbf{1 9}, \mathbf{2 0}, \mathbf{1 5}]$.

Streptozotocin-Nicotinamide injection caused diabetes mellitus, which may be due to destruction of $\beta$ cells of the islet of langerhans of the pancreas [15]. Streptozotocin (STZ) is a widely used chemical inducer for Type 1 diabetes. STZ has been shown to produce free radicals in the body, which specifically cut DNA chains in the pancreatic beta cells, resulting in disorder of the function of the pancreatic beta cells and at a later phase, destruction of the beta cells by necrosis. Nicotinamide dinucleotide (NA) causes activation of the poly ADP ribose synthase to repair the damaged DNA [21]. The diabetic syndrome in rats administered STZ and partially protected with suitable dosages of nicotinamide is characterized by stable moderate hyperglycemia, glucose intolerance and altered but significant glucose stimulated insulin secretion [20, 22].

The present study observed the difference between the initial and final fasting plasma glucose levels of different groups of animal. The investigation revealed a significant elevation in blood glucose in diabetic control group as compared with normal animals at the end of the 14-day experimental period. Administration of EETO both $250 \mathrm{mg} / \mathrm{kg}$ and $500 \mathrm{mg} / \mathrm{kg}$ dose to diabetic rats showed a highly significant $(p<0.001)$ decrease in the levels of blood glucose (Table 3.3.1). The possible mechanism by which EETO brings about its hypoglycemic action in diabetic rats may be by potentiating the insulin effect of plasma by increasing either the pancreatic secretion of insulin from the existing beta cells or by its release from the bound form. The extract did not produce any significant effects on normal animals, which further confirms the safety and antidiabetogenic action of the extract. Various studies on medicinal plants have reported a similar blood glucose lowering activity $[20,15,23,33]$.

Diabetes is associated with profound alterations in plasma lipid and lipoprotein profile with an increased risk of premature atherosclerosis, coronary insufficiency and myocardial infarction [24]. The most common lipid abnormalities in diabetes are hypertriglyceridemia and hypercholesterolemia [25,26]. Accumulation of lipids in diabetes mediated through a variety of derangements in metabolic and regulatory processes, especially insulin deficiency, thereby rendering the diabetic patient more prone to hypercholesterolemia and hypertriglyceridemia.

One of the major pathogenesis of lipid metabolism disturbances in diabetes is the increased mobilization of fatty acids from adipose tissue and secondary elevation of free fatty acid level in the blood [27].Excessive lipolysis has been found to occur during diabtes. One of the consequences of excessive mobilization of fatty acid is the production of ketone bodies in the liver. The excessive lipolysis in diabetic adipose tissue leads to increase free fatty acids in circulation. They enter the liver and are esterified to form triglycerides [14]. Fatty acids are required for both structure and function of every cell in the body and they form an important component of cell membranes. Several authors have reported that, the fatty acid compositions of various tissues are altered in both experimental and human diabetes [14,28]. Diabetes is also known to be 
associated with an increases in the synthesis of cholesterol, which may be due to the increased activity of HMG CoA reductase [14].

A number of observations indicate that plasma HDL cholesterol is low in untreated insulin-deficient diabetic, which was associated with a decline in HDL-turnover rate. A marked increase in total cholesterol and decrease in HDL cholesterol have been observed in untreated diabetic rats [14].Under normal circumstances insulin activates enzyme lipoprotein lipase and hydrolyses triglycerides. Insulin deficiency results in failure to activate the enzymes thereby causing hypertriglyceridemia $[\mathbf{1 5 , 1 4 ]}$. Hypertriglyceridemia is a common finding in patients with diabetes mellitus and is responsible for vascular complications [20]. Hypertriglyceridemia is also associated with metabolic consequences of hypercoagulability, hyperinsulinemia, insulin resistance and insulin intolerance [29].

Lowering of serum lipids concentration through dietary or drug therapy seems to be associated with a decrease in the risk of vascular diseases.In this study, administration of the extract both $250 \mathrm{mg} / \mathrm{kg}$ and 500 $\mathrm{mg} / \mathrm{kg}$ dose to the STZ-Nicotinamide induced diabetic rats significantly $(p<0.05, p<0.01$ respectively) improved these parameters (Table 3.3.2). The observed hypolipidaemic effect may be because of decreased cholesterogenesis and fatty acid synthesis. Significant lowering of total cholesterol and raise in HDL cholesterol is a very desirable biochemical state for prevention of atherosclerosis and ischaemic conditions. Various studies on medicinal plants have reported a similar lipid lowering activity [27,30,31].The significant control of the levels of serum lipids in the aqueous extract treated diabetic rats may be directly attributed to improvements in insulin levels upon EETO therapy.

Induction of diabetes with STZ is associated with the characteristic loss of body weight which is due to increased muscle wasting in diabetes [15] and due to loss of tissue proteins[32]. Diabetic rats treated with the EETO showed an increase in body weight as compared to the diabetic control,(Table 3.3.3) which may be due to its protective effect in controlling muscle wasting i.e. reversal of gluconeogenesis and may also be due to the improvement in insulin secretion and glycemic control.

Histopathology studies also supported our findings. The number of functionally intact $\beta$-cells in the islet organ is of decisive importance for the development course and outcome of diabetes mellitus. The renewal of $\beta$-cells in diabetes has been studied in several animal models. The total $\beta$-cell mass reflects the balance between the renewal and loss of these cells. It was also suggested that regeneration of islet $\beta$-cells following destruction by STZ may be the primary cause of the recovery of STZ-injected rats from the effects of the drug. In our studies, the damage of pancreas in STZ-treated diabetic control rats (Figure 3.4b) and regeneration of $\beta-$ cells by glibenclamide (Figure 3.4c) was observed. The comparable regeneration was also shown by EETO at a dose of $500 \mathrm{mg} / \mathrm{kg}$ (Figure 3.4e). Histopathological data in our studies reinforce healing of pancreas, by EETO, as a plausible mechanism of their antidiabetic activity.

The phytochemical screening result showed that EETO contains high amounts of phenolics, tannins, flavanoids and terpenoids.Other constituents like saponins and alkaloids were present in low amounts. These phytochemical constituents are known to be hypoglycemic. In the light of our pharmacological studies it can assume that, the antidiabetic activity of EETO may be due to the presence of these phytoconstituents, especially due to flavanoids.Further experiment should be carried out for isolating the possible hypoglycemic and hypolipidemic compounds and then explain the actual mechanism of antidiabetic actions of the plant extract. The present study has given some preliminary idea of the hypoglycemic and hypolipidemic compounds present in the ethanolic extract of T.orientalis leaves.

This study would be helpful for the human subject to produce herbal formulation with less side effects and cost effective treatment for diabetes. Further work at biomolecular level in genetically modified diabetic rats and clinical trials of the extracts and formulations will ensure that the formulation meets the global standard and acceptability.

\section{Acknowledgments}

I thank Mr.C.Pramod (Sr.Lecturer, UCP, Cheruvandoor) for guidance, Mrs.Bobby.S.Prasad(Sr.Lecturer,UCP, Cheruvandoor) for encouragement. Also I thank Dr.Sibi P.I (Head, Department of Pharmacology), and all the staff of University college of pharmacy, Cheruvandoor, Kottayam , especially Mrs.Litty Madam, Dr.Rossamma Thomas, MD, D.C.P, Pathologiost, Dianova Laboratoriesfor providing lab facilities and extending help whenever necessary.I thank DR.P.Muralidharan for helpful suggestions in the preparation of this paper.

\section{References}

[1]. Prasad SK, Kulshreshtha A, Qureshi TN. Antidiabetic Activity of Some Herbal Plants in Streptozotocin Induced Diabetic Albino Rats. Pakistan Journal of Nutrition 2009;8(5):551-557.

[2]. Kumar PM, Sasmal D, Mazumber PM. The antihyperglycemic effect of aerial parts of Salvia splendens(scarlet sage) in streptozotocin-induced diabetic-rats. Pharmacognosy Research 2010;2(3):190-194. 
[3]. Yadav S, Vats V, Dhunnoo Y, Grover JK. Hypoglycemic and Antihyperglycemic activity of Murraya koenigii leaves in diabetic rats. J.Ethanopharmacol 2002;82:111-116.

[4]. Grover JK, Vats V, Rathi SS, Dawar R. Traditional Indian Antidiabetic plants attenuate the progression of renal damage in STZ induced diabetic Mice. J.Ethanopharmacol 2001;76:233-238.

[5]. Jarald E, Joshi SB, Jain DC. Diabetes and Herbal Medicines. Iranian Journal of Pharmacology and Therapeutics 2008;7:97-106.

[6]. Holman RR, Turner RC. Oral agents and insulin in the treatment of NIDDM. In:Pickup J, Willians G editors. Text book of Diabetes. Oxford:Blackwell;1991.

[7]. Kesari AN, Gupta RK, Singh SK, Diwakar S, Watal G. Hypoglycemic and antihyperglycemic activity of Aegal marmelos seed extracts in normal and diabetic rats. J.Ethanopharmacol 2006;107:374-379.

[8]. Gupta RK, Kesari AN, Murthy PS, Chandra R, Tandon V, Watal G. Hypoglycemic and antidiabetic effect of ethanolic extract of leaves of Annona squamosa L.in experimental animals. J.Ethanopharmacol 2005;99:75-81.

[9]. Tchamo DN, Mariotte AM, Cartier G, Dijoux-Franca MG, Tsamo E. Xanthones and Other Constituents of Trema orientalis. Pharmaceutical Biology 2001;39:202-205.

[10]. The Catalogue of Medicinal Plant Resources in Taiwan, $1^{\text {st }}$ ed. Editorial Committee on Chinese Medicine and Pharmacy, Department of Health, Executive Yuan, Taipei, Taiwan 2003,1;163.

[11]. kuo W-L, Huang Y-L, Wang S-T, Ching LiNi, Shien B-J, Chen C-C. Chemical Constituents of Trema orientalis. J Chin Med 2007; 18:27-36.

[12]. www.medicinalplantsofBangladesh.com/file//D:/TREMA\%20ORIENTALIS\% 20(L)\%20BI.htm (Cited 2012 Feb $\left.12^{\text {th }}\right)$.

[13]. Shirwaikar A, Rajendran K, Kumar D, Bodla R. Antidiabetic activity of aqueous leaf extract of Annona squamosa in streptozotocin-nicotinamide type 2 diabetic rats. J.Ethanopharmacol 2003;91:171-175.

[14]. Ravi K, Rajasekaran S, Subramanian S.Antihyperlipidemic effect of Eugenia jambolana seed kernel on streptozotocin-induced diabetes in rats.Food and Chemical Toxicology 2005;43:1433-1439.

[15]. Shirwaikar A, Rajendran K, Barik R. Effect of aqueous bark extract of Garuga pinnata Roxb. In streptozotocin-nicotinamide induced type-II diabetes mellitus. J.Ethanopharmacol 2006;107:285-290.

[16]. Latner A. Clinical Biochemistry. Saunders:Philadelphia 1958:48.

[17]. American Diabetes Association. Standards of medical care for patients with diabetes mellitus. Diabetes Care 1998;21:22-31.

[18]. http://diabetes.about.com/od/symptomsdiagnosis/a/ogtt.htm. [cited 2010 Nov12th].

[19]. Islam A, Akhthar A, Khan RI, Hossain S, Alam K, Wahed II et al . Oral Glucose Tolerance Test (OGTT) In Normal Control And Glucose Induced Hyperglycemic Rats With Coccinia cordifolia L. And Catharanthus roseus L.Pak. J. Pharm. Sci 2009;22(4):402404.

[20]. Shirwaikar A, Rajendran K, Punitha ISR. Antidiabetic activity of alcoholic stem extract of Coscinium fenestratum in streptozotocin nicotinamide induced type 2 diabetic rats. J.Ethanopharmacol 2004;97:369-374.

[21]. Firdous M, Koneri R, Sarvaraidu CH, Harish M, Shubhapriya KH. Antidiabetic activity of Saponins of Momordica Cymbalaria in Streptozotocin-Nicotinamide NIDDM Mice. Journal of Clinical and Diagnostic Research 2009;3:1460-1465.

[22]. Masiello P, Broca C, Gross R, Roye M, Manteghetti M, Hillaire- Buys D, Novelli M, Ribes G. Development of a new model of type 2 diabetes in adult rats administered with streptozotocin andnicotinamide. Diabetes 1998; 47:224-228.

[23]. Tan BKH, Tan CH, Pushparaj P. Effects of Averrhoa bilimbi leaf extract on blood glucose and lipids in streptozotocin-diabetic rats. J.Ethanopharmacol 2000;72:69-76.

[24]. Goodman LS, Gilman A, editors. The Pharmacological Basis of Therapeutics. New York: Macmillan, Inc;1985:1490-1510.

[25]. Khan BA, Abraham A, Leelamma S. Hypoglycemic action of Murraya koenigii (curry leaf), Brassica juncea (mustard); mechanism of action. Indian Journal of Biochemistry and Biophysics 1995;32:106-108.

[26]. Mitra SK, Gopumadhavan S, Muralidhar TS, Anturlikar SD, Sujatha MB. Effect of D-400, a herbomineral preparation on lipid profile, glycated hemoglobin and glucose tolerance in STZ induced diabetes in rats. Indian Journal of Experimental Biology 1995; 33:798-800.

[27]. Ram A, Lauria P, Gupta R, Kumar P, Sharma VN. Hypocholesterolemic effects of Terminalia arjuna tree bark. J.Ethanopharmacol 1997;55:165-169.

[28]. Tilvis RS, Miettinen TA.Fatty acid composition of serum lipids, erythrocytes and platelets in insulin-dependent diabetic women. Journal of Clinical Endocrinology and Metabolism 1985;61:741-745.

[29]. Gingsberg HN. Lipoprotein metabolism and its relationship to atheroscelrosis. Medicinal and clinical North America 1994;78:1-20.

[30]. Sharma SR, Dwivedi SK, Swarup D. Hypoglycaemic, antihyperglycaemic and hypolipidemic activities of Caesalpinia sylvestre seeds in rats. J.Ethanopharmacol 1997; 58:39 - 44.

[31]. Jouad H, Lemhadri A, Maghrani M, Ali ZN, Eddouks M.Cholesterol lowering activity of the aqueous extract of Spergularia in normal and recent onset diabetic rats. J.Ethanopharmacol 2003; 87: 43-49.

[32]. Chatterjea MN, Shinde R.Text Book of Medical Biochemistry. Jaypee Brothers Medical Publishers, New Delhi; $2002: 317$.

[33]. Shirwaikar A, Rajendran K, Kumar D, Bodla R. Antidiabetic activity of aqueous leaf extract of Annona squamosa in streptozotocin-nicotinamide type 2 diabetic rats. J.Ethanopharmacol 2003;91:171-175. 